УДК 316

$10.17213 / 2075-2067-2020-5-175-181$

\title{
АНАЛИЗ РЕАЛИЗАЦИИ ЭКОЛОГИЧЕСКОГО МЕНЕДЖМЕНТА ПОТОКАМИ АВТОМОБИЛЬНОГО ТРАНСПОРТА В БОЛЫШОМ ГОРОДЕ
}

\author{
(C) 2020 г. В. Г. Ларионов ${ }^{*}$ В. В. Ларичкин ${ }^{* *}$, И. А. Сажин ${ }^{* *}$
}

"Московский государственный технический университет имени Н. Э. Баумана, 2. Москва, Россия

"Новосибирский государственный технический университет, г. Новосибирск, Россия

Целью исследования является анализ реализачии экологического менеджмента потоками автомобильного транспорта в большом городе с силу очевидной необходимости поиска новых путей и подходов к решению проблем загрязнения атмосферного воздуха выхлопными газами двигателями внутреннего сгорания. Основным из таких универсальных путей в мире общепризнан экологический менеджмент.

Методологическую базу исследования представляют работы в области системы экологического менеджмента (3. В. Туриева, А.Л. Боброва, Н. В. Пахомовой, А. Эндерса, K. Рихтера и др.), атмосферной диффузии (математические модели построены на основании регламентированной методики). Исследование показывает возможность непосредственного применения экологического менеджмента как системы управления потоками автомобильного транспорта, являющихся основными источниками выбросов загрязняюших веществ в атмосферу города.

Результаты исследования. В результате исследования проведен анализ основных структурных элементов экологического менеджмента применительно к конкретным потокам автомобильного транспорта в большом городе. Построенные модели участков городских магистралей как площадные источники выбросов загрязняющих веществ рассмотрены как объекты системы экологического менеджмента.

Перспективу исследования составляет объективная необходимость снижения загрязнения атмосферного воздуха в больших городах с помощью широкого применения систем экологического менеджмента.

Ключевые слова: экологический менеджмент; город; автомобильный транспорт; загрязняющие вещчества.

\section{ANALYSIS OF THE IMPLEMENTATION OF ENVIRONMENTAL MANAGEMENT BY ROAD TRANSPORT FLOWS IN A BIG CITY}

\section{(C) 2020 V. G. Larionov*, V. V. Larichkin**, I. A. Sazhin ** \\ "Bauman Moscow State Technical University, Moscow, Russia "Novosibirsk State Technical University, Novosibirsk, Russia}

The purpose of the study is to analyze the implementation of environmental management of traffic flows in a large city due to the obvious need to find new ways and approaches to solving the problems of air pollution by exhaust gases from internal combustion engines. Environmental management is generally recognized as the main such way in the world. 
The methodological base of the study is to represented by work in the field of environmental management system (Z.V. Turiev, A.L. Bobrov, N.V. Pakhomova, A. Enders, K. Richter, etc.), atmospheric diffusion (mathematical models are built on the basis of regulated techniques). The study shows the possibility of direct application of environmental management as a system for managing trafficflows, which are the main sources of pollutant emissions into the city's atmosphere.

The results of the study. The analysis of the main structural elements of environmental management in relation to specific flows of road transport in a big city was carried out. The constructed models of sections of city highways, as areal sources of emissions of pollutants, are considered as objects of the environmental management system.

The prospect of the study is the objective need to reduce air pollution in large cities through the widespread use of environmental management systems.

Key words: environmental management; town; automobile transport; pollutants.

Введение. Выхлопные газы (или отработавшие газы) 一 основной источник токсичных веществ от двигателя внутреннего сгорания $[5,6,7]$. Это неоднородная смесь различных газообразных веществ с разнообразными химическими и физическими свойствами, состоящая из продуктов полного и неполного сгорания топлива, избыточного воздуха, аэрозолей и различных микропримесей (как газообразных, так и в виде жидких и твердых частиц), поступающих из цилиндров двигателей в его выпускную систему. В своем составе они содержат около 300 веществ, большинство из которых токсичны. Основными нормируемыми токсичными компонентами выхлопных газов двигателей являются оксиды углерода, азота и углеводороды. Оксиды азота являются одними из наиболее токсичных компонентов отработавших газов $[4,5]$. Сгоревшие не полностью углеводороды выбрасываются с выхлопными газами в атмосферу. Они являются причиной многих хронических заболеваний. Пары бензина токсичны, допустимая среднесуточная концентрация паров бензина составляет 1,5 (мг/куб. м). Содержание углеводородов в выхлопных газах возрастает при работе двигателя на режимах принудительного холостого хода. Углеводороды (олефины) и оксиды азота при определенных метеорологических условиях активно способствуют образованию смога. Он представляет собой аэрозоль, состоящий из дыма, тумана, пыли, частичек сажи, капелек жидкости (во влажной атмосфере), возникает в атмосфере промышленных городов при определенных метеорологических условиях.
В настоящее время на долю автомобильного транспорта приходится больше половины всех вредных выбросов в окружающую среду, которые являются главным источником загрязнения атмосферы, особенно в крупных городах [3]. В среднем при пробеге 15 тыс. км за год каждый автомобиль сжигает 2 т топлива и около 26-30 т воздуха, в том числе 4,5 т кислорода, что в 50 раз больше потребностей человека. При этом автомобиль выбрасывает в атмосферу (кг/год): угарного газа - 700, диоксида азота - 40, несгоревших углеводородов - 230 и твердых веществ - 2-5. Кроме того, выбрасывается много соединений свинца из-за применения в большинстве своем этилированного бензина. Наблюдения показали, что в домах, расположенных рядом с большой дорогой (до 10 м), жители болеют раком в 3-4 раза чаще, чем в домах, удаленных от дороги на расстояние 50 м.

Общая картина загрязнения атмосферного воздуха в городах Российской Федерации продолжает ухудшаться, несмотря на отдельные успехи и достижения [3]. Основная причина этого заключается в постоянном увеличении автомобильного парка городов, низкой эффективности используемых защитных мероприятий, отсутствии надлежащего мониторинга уровня загрязнения атмосферного воздуха.

Все более очевидной становится необходимость поиска новых путей и подходов к решению экологических проблем промышленного производства. Основным из таких путей в мире общепризнан экологический менеджмент. Целесообразно реализовать 
экологический менеджмент как тип управления, принципиально ориентированный на формирование и развитие экологических технологий и экологической культуры жизнедеятельности человека. Новая концепция экологического менеджмента в рассматриваемом случае включает полный комплекс проблем управления, связанных с распространением загрязняющих веществ от двигателей внутреннего сгорания в условиях большого города. Необходимо сформировать математическую - статистическую максимально достоверную модель объекта управления, выделить элементы подлежащие регулированию.

Формирование математической - статистической модели объекта управления. В качестве примера, не уменьшающего общность рассуждений, выбран г. Новосибирск. Более $60 \%$ общего количества ЗВ в атмосфере города от автомобильного транспорта [1, 4]. Основные городские магистрали имеют три или четыре полосы в каждом направлении, тротуары, жилая застройка, как правило, находится на расстоянии 20-50 м от проезжей части улицы, длина таких улиц варьируется от 1 до 5 км, исключение - Красный проспект длиной около 10 км, по которому движение грузового автотранспорта запрещено. В качестве расчетных моделей целесообразно рассмотреть автомобильные городские магистрали с двумя, тремя и четырьмя полосами движения в каждом направлении. Продолжительность пробки протяженностью 1 км составляет в среднем 60 мин. Среднестатистическое количество автомобилей на расчетной длине улицы с четырьмя полосами движения в каждом направлении: грузовые автомобили (дизели) с разрешенной массой более 5 тонн - 120 единиц (20\% от общего числа), грузовые автомобили (бензиновые двигатели) с разрешенной массой до 5 тонн - 180 единиц (30\% от общего числа), автобусы вместимостью до 50 пассажиров - 60 единиц (10\% от общего числа), легковые автомобили 240 единиц (40\% от общего числа). Скорость движения в пробке не превышает 10 км в час, поэтому источник выбросов ЗВ можно считать стационарным, площадным, у которого длина в 10-15 раз больше ширины.

В представленной работе применена регламентируемая методика [7] для моделирова- ния распространения ЗВ от автомобильного транспорта с 2-мя, 3-мя, 4-мя полосами движения в каждом направлении, длина пробки принята равной 1 км. Жилая застройка расположена на расстоянии 20-30 м от границы автомобильной части улицы. Вычисления выполнены конечно-разностным методом [4].

Анализ полученных данных. Определеныобластираспространениядиоксидаазотакак наиболее характерные для рассматриваемого вида выбросов загрязняющих веществ. Значения средних концентраций диоксида азота: для 8-полосной магистрали — 98,1 (мкг/куб.м), для 6-полосной - 86,6(мкг/ куб. м), для 4-полосной - 60,2(мкг/куб. м). Величины наибольших значений концентраций диоксида азота увеличиваются по сравнению со средними значениями в 2,5 раз, 2,46 раз, 1,75 раз для 8-, 6-, 4-полосных магистралей соответственно. Полученные результаты соответствуют результатам исследований $[2,5,6]$. Авторами показана возможность превышения ПДК диоксида азота от 6,9 до 8,5 раз относительно ПДК в случае максимальной концентрации автотранспортных средств на городских улицах. В работе [6] было выявлено, что у 53\% проб, собранных на расстоянии менее 20 метров от автодорог, концентрация диоксида азота превысила 40мкг/куб. м, а 30\% проб, собранных на расстоянии от 20 до 50 метров от автодорог, показали средний результат 30 40 мкг/куб. м. В Москве и городах-спутниках было собрано 78 проб, 17 были установлены на расстоянии менее 20 метров от автодорог, из которых 11 из них показали концентрацию более 40 мкг/куб. м. Максимальные концентрации диоксида азота - 101 мкг/куб. м - зафиксированы на пересечении Бакинской улицы и Кавказского бульвара; 78,71 мкг/куб. м вблизи ул. Нижняя Масловка [2].

Полученные данные о состоянии атмосферного воздуха позволяют в полном объеме применить методы экологического менеджмента для достижения поставленных целей. Ведущими являются административные методы, направленные на принуждение природопользователей к рациональному потреблению природных ресурсов и сохранению качества окружающей среды:

— экологическая экспертиза конкретной городской магистрали; 
- применение экологических нормативов, норм и стандартов на этапах проектирования, строительства, эксплуатации объекта;

- установление запретов или ограничений по экологическим показателям, что широко используется в природоохранной практике;

- применение штрафных санкций за нарушение экологических нормативов, природоохранных законов, правил и других административных мер, включая самые жесткие меры. Например, в США в соответствии с Законом о чистом воздухе владелец или водитель городского автобуса, не соблюдающий требование работы на низкозагрязняющем топливе, подвергается штрафу до 25 тыс. долл. за каждый день такого нарушения. В ряде регионов нашей страны, в том числе Москве, действуют подразделения экологической милиции, которые выявляют нарушителей природоохранного законодательства и предъявляют им штрафные санкции.

В последнее время наряду с административными методами широко применяются экономические методы. Разработано множество экономических инструментов, направленных на обеспечение экологической безопасности, включая экономическое стимулирование природоохранной деятельности, экологическое страхование, совершенствование налоговой системы с учетом экологического фактора, предоставление кредитов на льготных условиях как форму поощрения за экономию ресурсов, введение дифференцированных цен на экологически «чистую» и «грязную» продукцию и т.П. Государство может оказывать финансовую поддержку природопользователям, осуществляющим мероприятия по охране окружающей среды, в разных формах:

- денежные субсидии для освоения экологически чистых технологий, продукции;

- выделение целевых займов и кредитов предприятиям, желающим реализовать технологии, улучшающие экологию атмосферного воздуха в городе;

- создание режима ускоренной амортизации экологической техники;

- налоговые льготы по вложению инвестиций на природоохранные цели;

— поощрение развития экобизнеса.

Заключение. В статье акцентировано внимание на проблеме выхлопных газов ав- томобильного транспорта как основном источнике токсичных загрязняющих веществ в атмосфере большого города. Проведено обоснование экологического менеджмента в качестве основного общепризнанного механизма управления, принципиально ориентированного на формирование и развитие экологических технологий и экологической культуры жизнедеятельности человека. Представлены расчеты величин концентрации загрязняющих в атмосфере городских магистралей. Полученные данные соответствуют известным результатам. Каждый элемент этой системы (городская автомобильная пробка) должен рассматриваться в качестве источника выбросов загрязняющих веществ в атмосферу города повышенной интенсивности. Изложен спектр методов экологического менеджмента применительно к проблеме загрязнения атмосферы мегаполиса. Выполненный в данной работе анализ показал целесообразность практического внедрения в полном объеме экологического менеджмента применительно к системе «городские магистрали - автомобильный транспорт» как объекту управления. Перспективность исследования обусловлена объективной необходимостью снижения загрязнения атмосферного воздуха в больших городах с помощью широкого применения систем экологического менеджмента.

\section{Литература}

1. Государственный доклад «О состоянии и об охране окружающей среды Новосибирской области в 2016 году». - Новосибирск, 2017. - $212 \mathrm{c}$.

2. Интернет-документ. Диоксид азота в большом городе. Результаты исследования [Электронный ресурс] - Режим доступа: http://www.Greenpeace.ru/wpcontent/ upload/2018/10/report_tube.pdf. (Дата обращения: 26.03.2020).

3. Ларионов В.Г., Бадалова С.Г. Фалько А.Г. Экология. Менеджмент. Человек. М.: Издательскоторговая корпорация «Дашков и Ко», 2017. - 302 с.

4. Ларичкин В.В., Ларионов В.Г., Сажин И.А. Проблема переработки ТБО в Новосибирске в 2018 г. и возможные варианты решения // Контроллинг. - 2018. №68(2). - C. 28-35. 
5. Ложкин В.Н., Ложкина О.В. Комплексный экспериментальный и расчетный мониторинг и прогнозирование загрязнения воздуха автотранспортом с использованием национальных и европейских подходов / НИР, МЧС России, СПб У ГПС МЧС России. Заключительный отчет, № гос. регистрации 114080630031, 2015 г. - 3,5 п.л.

6. Магдеева А. Р., Шагидуллин А.Р., Гилязова А. Ф., Амирянова Г.Ф., Шагидуллин Р.Р. Анализ структуры выбросов загрязняющих веществ от автотранспорта на территории г. Казани. // Российский журнал прикладной экологии. - 2016. - №1. - С. 33-37.

7.ПриказМинприродыРФ от 06.06.2017 г. №273 «Об утверждении методов расчетов рассеивания выбросов вредных (загрязняющих) веществ в атмосферном воздухе».

\section{Referense}

1. Gosudarstvennyj doklad «O sostojanii i ob ohrane okruzhajushhej sredy Novosibirskoj oblasti v 2016 godu» [State report «On the state and environmental protection of the Novosibirsk region in 2016»). - Novosibirsk, 2017. - 212 p.

2. Internet-dokument. Dioksid azota v bol'shom gorode. Rezul'taty issledovanija [Internet document. Nitrogen dioxide in a big city. The results of the research] [Jelektronnyj resurs] — URL: http://www.Greenpeace.ru/ wpcontent/upload/2018/10/report tube.pdf. (Date accessed: 26.03.2020).

3.Larionov V.G., Badalova S. G. Fal'koA. G. Jekologija. Menedzhment. Chelovek [Manage- ment. Man]. - Moscow: Izdatel'-skotorgovaja korporacija «Dashkov i Ko», 2017. — 302 p.

4. Larichkin V.V., Larionov V.G., Sazhin I.A. Problema pererabotki TBO v Novosibirske v 2018 g. i vozmozhnye varianty reshenija [The Problem of MSW management in Novosibirsk in 2018 and possible solutions] // Kontrolling [Controlling]. — 2018. — №68 (2). - Pp. 28-35.

5. Lozhkin V.N., Lozhkina O.V. Kompleksnyj jeksperimental'nyj i raschetnyj monitoring i prognozirovanie zagrjaznenija vozduha avtotransportom s ispol'zovaniem nacional'nyh i evropejskih podhodov [Integrated experimental and computational monitoring and forecasting air pollution from vehicles using the national and European approaches] / NIR, MChS Rossii, SPb U GPS MChS Rossii. Zakljuchitel'nyj otchet, № gos. registracii 114080630031, 2015 g. - 3,5 p.l.

6.Magdeeva A. R., Shagidullin A. R., Giljazova A.F., Amirjanova G.F., Shagidullin R.R. Analiz struktury vybrosov zagrjaznjajushhih veshhestv ot avtotransporta na territorii g. Kazani [Analysis of the structure of emissions of pollutants from vehicles on the territory of Kazan]. // Rossijskij zhurnal prikladnoj jekologii [Russian journal of applied ecology]. - 2016. №1. - Pp. 33-37.

7.PrikazMinprirody RF ot 06.06.2017 g. №273 «Ob utverzhdenii metodov raschetov rasseivanija vybrosov vrednyh (zagrjaznjajushhih) veshhestv v atmosfernom vozduhe») [Order of the Ministry of natural resources of the Russian Federation dated 06.06.2017 №273 «On approval of methods for calculating the dispersion of emissions of harmful (polluting) substances in atmospheric air»]. 


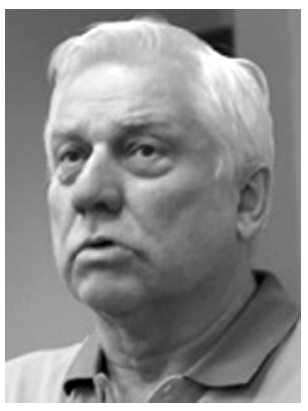

Ларионов Валерий Глебович - доктор экономических наук, профессор кафедры «Экономика и организация производства» МГТУ им. Н.Э. Баумана, автор более 30 монографий и учебных пособий, специалист в области стратегического менеджмента, экологического менеджмента, психологии управления, проблем продовольственной безопасности, автор более чем 350 статей в отечественных и 50 зарубежных журналах, член Международной ассоциации экономистов, преподавателей Высшей школы, член комитета США по логистике, международный журналист, почетный работник Высшей школы.

Larionov Valery Glebovich - Doctor of Economic Sciences, Professor of the Department of Economics and Organization of Production, Bauman Moscow State Technical University, author of over 30 monographs and textbooks, specialist in the field of strategic management, environmental management, management psychology, food security problems, author of more than 350 articles in domestic and 50 foreign journals, member of the International Association of Economists, Graduate School teachers, member of the US Logistics Committee, international journalist, Honorary Worker of the Higher School.

105005, г. Москва, 2-я Бауманская ул., 5, стр. 1

5 2nd Baumanskaya st., bld. 1, 105005, Moscow, Russia

E-mail: vallarionov@yandex.ru

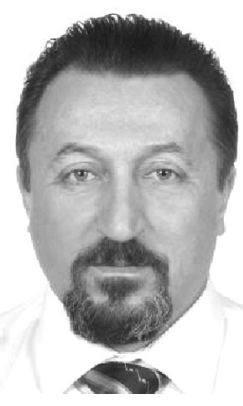

Ларичкин Владимир Викторович - доктор технических наук, профессор, заведующий кафедрой «Инженерные проблемы экологии» Новосибирского государственного технического университета, автор 5 монографий, более 100 статей в отечественных и зарубежных журналах, специалист в областях оптимизации аппаратов мокрой очистки газов угольных электростанций, технологии переработки и утилизации техногенных образований и отходов, разработки методов количественного анализа сыпучести гранулированных зернистых катализаторов.

Larichkin Vladimir Viktorovich - Doctor of Engineering Sciences, Professor, Head of the Department of Engineering Ecology Problems, Novosibirsk State Technical University, author of 5 monographs, more than 100 articles in domestic and foreign journals, an expert in the fields of optimization of devices for wet cleaning of gases from coal-fired power plants, processing technology and utilization of technogenic formations and waste, development of methods for quantitative analysis of the flowability of granular granular catalysts.

630073, г. Новосибирск, пр. К. Маркса, 20

20 K. Marksa av., 630073, Novosibirsk, Russia

E-mail: larichkin@corp.nstu.ru 


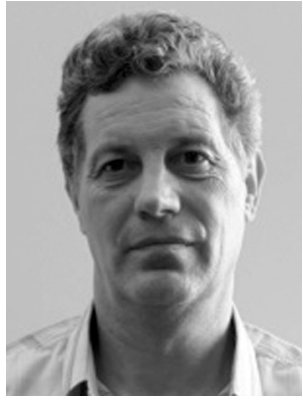

Сажин Игорь Александрович - кандидат технических наук, доцент кафедры технической теплофизики Новосибирского государственного технического университета, автор 3 монографий и учебных пособий, более 30 статей в отечественных и зарубежных журналах, специалист в областях промышленной экологии, технической теплофизики.

Sazhin Igor Aleksandrovich - Candidate of Engineering Sciences, Associate Professor of the Department of Technical Thermophysics, Novosibirsk State Technical University, author of 3 monographs and textbooks, more than 30 articles in domestic and foreign journals, an expert in the fields of industrial ecology, technical thermal physics.

630073, г. Новосибирск, пр. К. Маркса, 20

20 K. Marksa av., 630073, Novosibirsk, Russia

E-mail: sajinia@ngs.ru 